\title{
Criteria for Involving RES in Increasing the Energy Security of Isolated Inactive Areas of the North and Arctic Zone of the Russian Federation
}

\author{
Boris V. Lukutin*a, \\ Violetta R. Kiushkina ${ }^{b, c}$ and Ivan S. Ivanov ${ }^{b}$ \\ ${ }^{a}$ National Research Tomsk Polytechnic University \\ Energy Engineering School \\ Tomsk, Russian Federation \\ ${ }^{b}$ Federal State Budgetary Institution «Russian Energy Agency» \\ of the Ministry of Energy of Russia \\ Moscow, Russian Federation \\ ${ }^{c}$ Chukotsk branch of the North-Eastern Federal University \\ Scientific and educational center "Circumpolar Chukotka» \\ Anadyr, Russian Federation
}

Received 28.06.2021, received in revised form 25.07.2021, accepted 06.08.2021

\begin{abstract}
The article proposes the main criteria for involving renewable energy sources in improving the position of energy security in isolated hard-to-reach areas where decentralized power supply complexes operate under conditions of severe climatic changes and isolation. The considered criteria form the integrated value of renewable energy sources in ensuring energy security through a number of criteria such as resource significance, economic significance, environmental significance, energy significance. A group of indicators is proposed as part of the criteria, which is not limited to them, as well as the conditions for the formation of a gradation of threshold values of indicators with measurement tools are given. Schemes of analysis of resource indicators are given. Evaluation of the above criteria in accordance with the above methodology constitutes a criterion basis for a more efficient and optimal choice of the type of renewable energy sources, the option of combining renewable and traditional resources in the appropriate direction of ensuring and increasing the energy security of decentralized energy zones.
\end{abstract}

Keywords: energy security, criteria, group of indicators, renewable energy sources.

Citation: Lukutin B. V., Kiushkina V. R., Ivanov I. S. Criteria for involving res in increasing the energy security of isolated inactive areas of the north and arctic zone of the russian federation, J. Sib. Fed. Univ. Eng. \& Technol., 2021, 14(5), 507-519. DOI: $10.17516 / 1999-494 X-0329$

(C) Siberian Federal University. All rights reserved

This work is licensed under a Creative Commons Attribution-Non Commercial 4.0 International License (CC BY-NC 4.0).

* Corresponding author E-mail address: lukutin@mail.ru 


\title{
Критерии вовлечения ВИЭ в повышение
}

\section{энергетической безопасности изолированных \\ труднодоступных территорий Севера}

и Арктической зоны РФ

\author{
Б. В. Лукутин ${ }^{a}$, В.Р. Киушкина ${ }^{\tilde{\sigma}, \text { в }}$, И.С. Иванов ${ }^{\tilde{\sigma}}$ \\ ${ }^{a}$ Национальный исследовательский \\ Томский политехнический университет \\ Инженерная школа энергетики, \\ Российская Федераиия, Томск \\ ${ }^{6}$ Российское энергетическое агентство Минэнерго России \\ Российская Федерачия, Москва \\ ${ }^{\circ}$ Чукотский филиал Северо-Восточного федерального университета \\ Научно-образовательный центр «Циркумполярная Чукотка» \\ Российская Федераиия, Анадырь
}

Аннотация. Статья предлагает основные критерии вовлечения возобновляемых источников энергии в повышение позиций энергетической безопасности изолированных труднодоступных территорий, на которых функционируют децентрализованные энергетические комплексы электроснабжения в условиях суровых климатических изменений и изоляции. Рассматриваемые критерии формируют комплексную ценность возобновляемых источников энергии в обеспечении энергетической безопасности через ряд таких критериев, как ресурсная значимость, экономическая значимость, экологическая значимость, энергетическая значимость. Предложена группа индикаторов в составе критериев, не ограничивающаяся ими, а также приводятся условия формирования градации пороговых значений индикаторов с инструментарием измерения. Приведены схемы анализа ресурсных индикаторов. Оценка изложенных критериев в соответствии с приведенной методикой составляет критериальную основу для более эффективного и оптимального выбора типа возобновляемых источников энергии, варианта сочетания возобновляемых и традиционных ресурсов в соответствующем направлении обеспечения и повышения энергетической безопасности децентрализованных энергозон.

Ключевые слова: энергетическая безопасность, критерии, группа индикаторов, возобновляемые источники энергии.

Цитирование: Лукутин, Б.В. Критерии вовлечения ВИЭ в повышение энергетической безопасности изолированных труднодоступных территорий Севера и Арктической зоны РФ / Б. В. Лукутин, В. Р. Киушкина, И. С. Иванов // Журн. Сиб. федер. ун-та. Техника и технологии, 2021, 14(5). С. 507-519. DOI: 10.17516/1999-494X-0329

\section{Введение}

Нарастающая необходимость в устойчивой и эффективной энергетике, официальное признание необходимости использования возобновляемых источников энергии (ВИЭ) с увеличением их вклада в энергетический баланс страны мотивируют формирование инновационной укрепляющей позиции энергетической безопасности (ЭнБ) российских регионов в различных ее составляющих.

Дополнительные меры по обеспечению энергетической безопасности децентрализованных энергетических комплексов электроснабжения (ДЭКЭС) через сочетание доступных ис- 
точников возобновляемой энергии и традиционных энергоресурсов основаны на определении наиболее эффективных путей энергетического перехода к ВИЭ с разных точек зрения (достижение наиболее экономического решения, технологического совершенства, социального эффекта, целей экологической политики и т. д.) [1-6].

На сегодняшний день уже накоплено достаточно данных и знаний, касающихся структуры и опыта функционирования энергетических хозяйств в условиях высокой доли ВИЭ. Несмотря на это вопросы интеграции ВИЭ в каждом отдельном случае сопровождаются необходимостью решения индивидуальных задач и проблем, что особенно характерно для децентрализованных территорий. Рациональное построение гибридной автономной системы электроснабжения (АСЭС) с экономической и технической точек зрения вполне конкурентоспособно с традиционной децентрализованной энергетикой, основанной на ископаемом привозном топливе. ВИЭ хорошо вписываются в новые тренды, не требуя для развития, например, транспортной и сетевой инфраструктуры. В данном контексте создается благоприятная картина по объединению технологий ВИЭ, концепции распределенной генерации, принципа «Smart Grid», особенностей автономной энергетики с максимальной эффективностью на фоне назревшей необходимости решения проблем ЭнБ децентрализованных территорий Севера и Арктических зон. Для них укрепление отдельных позиций и в целом ЭнБ - это грань между стабильным и критическим существованием.

\section{Методы исследования}

Можно говорить о комплексной ценности (CV) ВИЭ в обеспечении ЭнБ децентрализованных территорий, которая будет характеризоваться сочетанием положительных эффектов и сопутствующих факторов, сопряженных с дополнительными расходами (затраты на совершенствование существующей структуры энергохозяйства: необходимость во внедрении современных технологий для обеспечения стабильности генерации при непостоянном характере проявления потенциала ВИЭ, в совершенствовании работы гибридного энергокомплекса, в прогнозировании выработки электроэнергии на основе ВИЭ, в замене низкоэффективного энергетического оборудования, дополнительные затраты на сетевую инфраструктуру и т. д.).

При выборе варианта участия ВИЭ в энергобалансе изолированной энергетической системы необходимы решения, максимально эффективные в условиях функционирования ДЭКЭС северных территорий: обеспечение безотказной работы, гарантированное энергоснабжение, удовлетворение спроса потребителей на энергию, снижение использования топливных энергоресурсов, улучшение экологической ситуации и т. д. Сокращение расходов на привозное дизельное топливо происходит на фоне высоких затрат на приобретение технологий возобновляемой энергетики. При этом необходимая модернизация существующих объектов локальной энергетики под внедрение новых технологий также требует инвестиций, в том числе логистическая составляющая на доставку оборудования новых технологий ВИЭ также будет имеет существенную позицию.

Данные факты способствуют «отложенному» экономическому эффекту для децентрализованной зоны электроснабжения, так как тарифы сокращаются в отдаленный срок и с медленной скоростью. Но со стороны эффектов от повышения надежности ДЭКЭС достижение наблюдается уже на стадии вовлечения ВИЭ.

$$
-509-
$$


Обобщенный алгоритм выбора оптимального варианта участия ВИЭ в решении проблемы «уязвимого места» энергетической безопасности изолированной энергозоны приведен на рис. 1.

Привлекательность развития ВИЭ - это общая характеристика совокупности признаков, факторов и средств, которые выделяют их ресурсы на фоне традиционных энергоресурсов и иных решений в диверсификации ТЭК и делают их интересными для повышения надежности АСЭС в укреплении позиций Эн Б. Коэффициент (степень) привлекательности развития ВИЭ будет расти в своем значении, если растет степень благоприятности, имеющая удачное сочетание своих составляющих. Но коэффициент снижается или обнуляется, если преобладает значение нейтрализующих ее факторов (рациональность подключения к централизованному электроснабжению, рациональность использования местных топливных ресурсов, высокие показатели надежности функционируемых АСЭС и т. д.).

Более развернутая оценка коэффициента привлекательности ВИЭ потребует определения эффекта при экономической оправданности (замещение топливных ресурсов и их сохранение), социального и экологического эффекта (избежание объема выбросов от замещаемых генерирующих мощностей), повышения эксплуатационной надежности и т. д., от реализации или исключения фактора привлекательности развития ВИЭ. Поэтому определение коэффициента

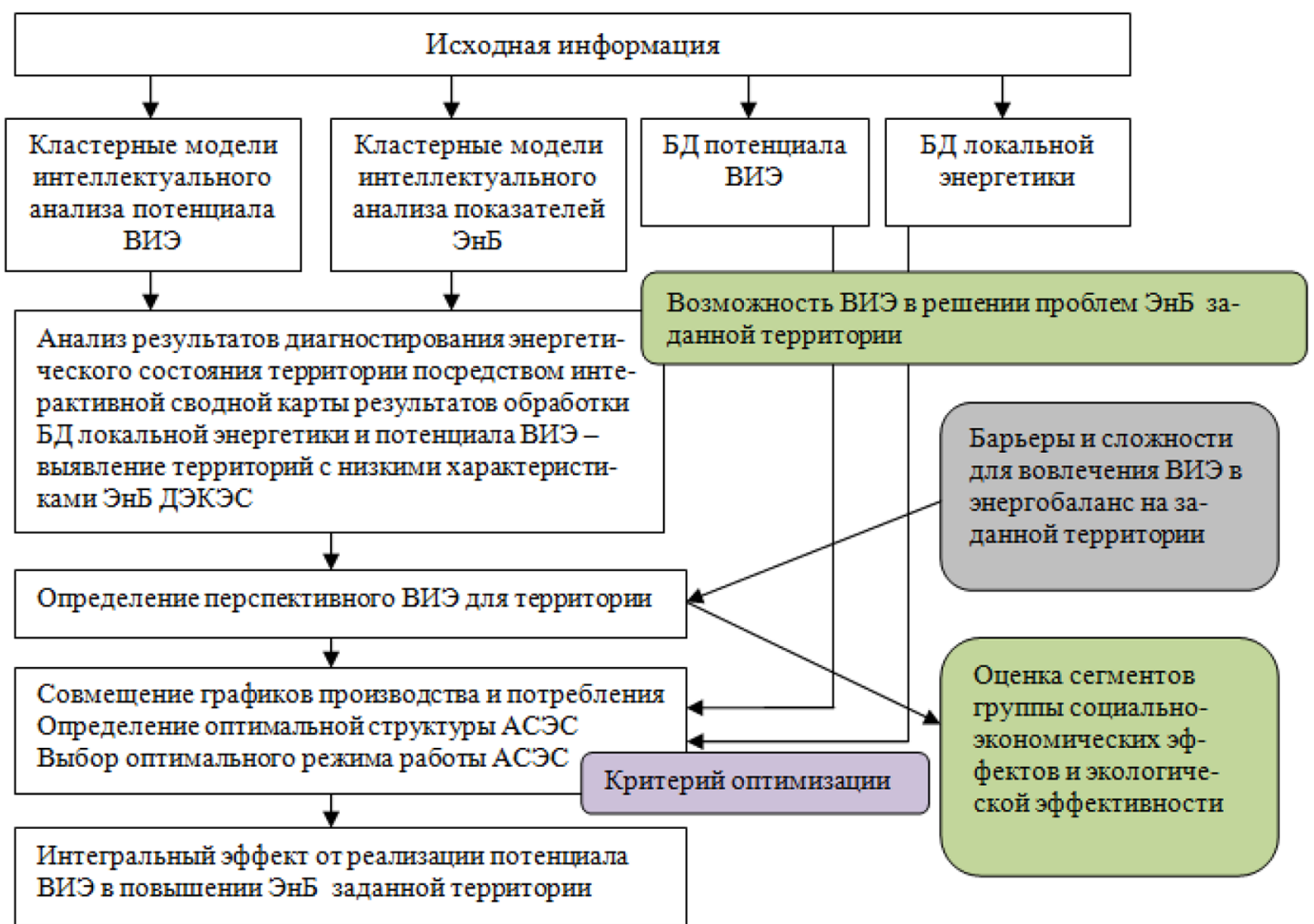

Рис. 1. Алгоритм выбора оптимальной структуры ДЭКЭС для децентрализованной зоны Севера и Арктических зон

Fig 1. Algorithm for choosing the optimal structure of a decentralized power supply complex for the decentralized zone of the North and the Arctic zones 
является достаточно емким исследованием, и однозначной расчетной формулой изображение инструментария не представляется возможным. Тогда здесь применима схема исследования, приведенная на рис. 2.

Определение действенного значения коэффициента привлекательности является весомым основанием по анализу факторов для перехода к блоку выбора оптимального варианта АСЭС с участием ВИЭ как укрепления позиций ЭнБ в ресурсной обеспеченности, надежности топливо- и электроснабжения, в экологической допустимости и социально-экономическом эффекте $[7,8]$.

Немаловажным критериальным фактором является и первоначальная оценка направленности добычи топливных ресурсов децентрализованной энергозоны - собственное потребление или экспорт. Данный показатель не преследует цель определения в своей формулировке. При анализе ЭнБ важно сопутствующее исследование того, как повлияют ситуации на ее состояние при существовании и появлении различных факторов, влияющих на оценку истощения запасов топливных ресурсов. Схема исследования представлена на рис. 3.

Например, при высоком индикаторе потребления собственных ресурсов мы принимаем уровень ЭнБ безопасным с благоприятным прогнозом на объемы извлекаемых запасов, кото-

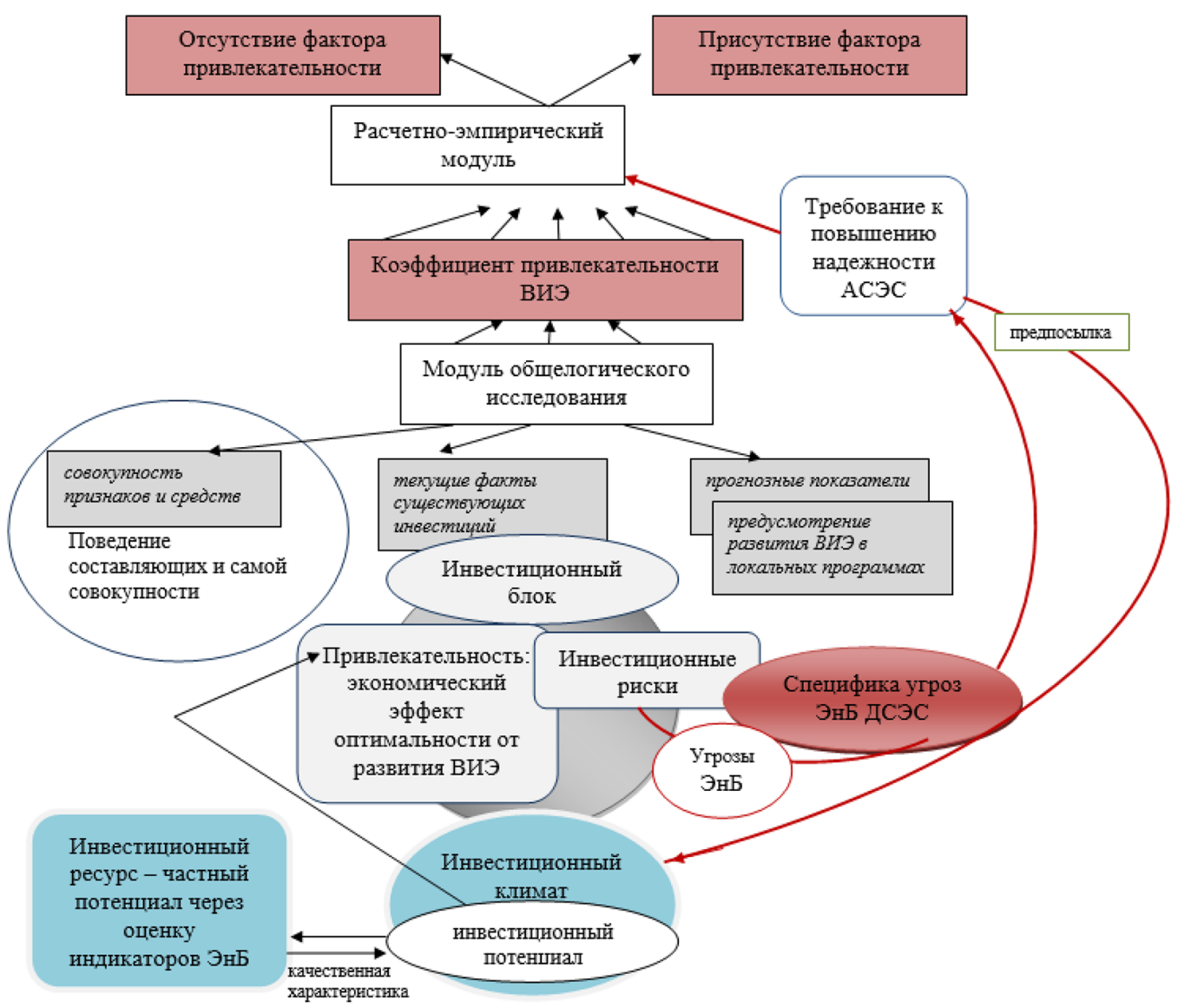

Рис. 2. Дерево этапов в определении коэффициента привлекательности ВИЭ

Fig 2. Tree of stages in determining the coefficient of attractiveness of renewable energy sources 


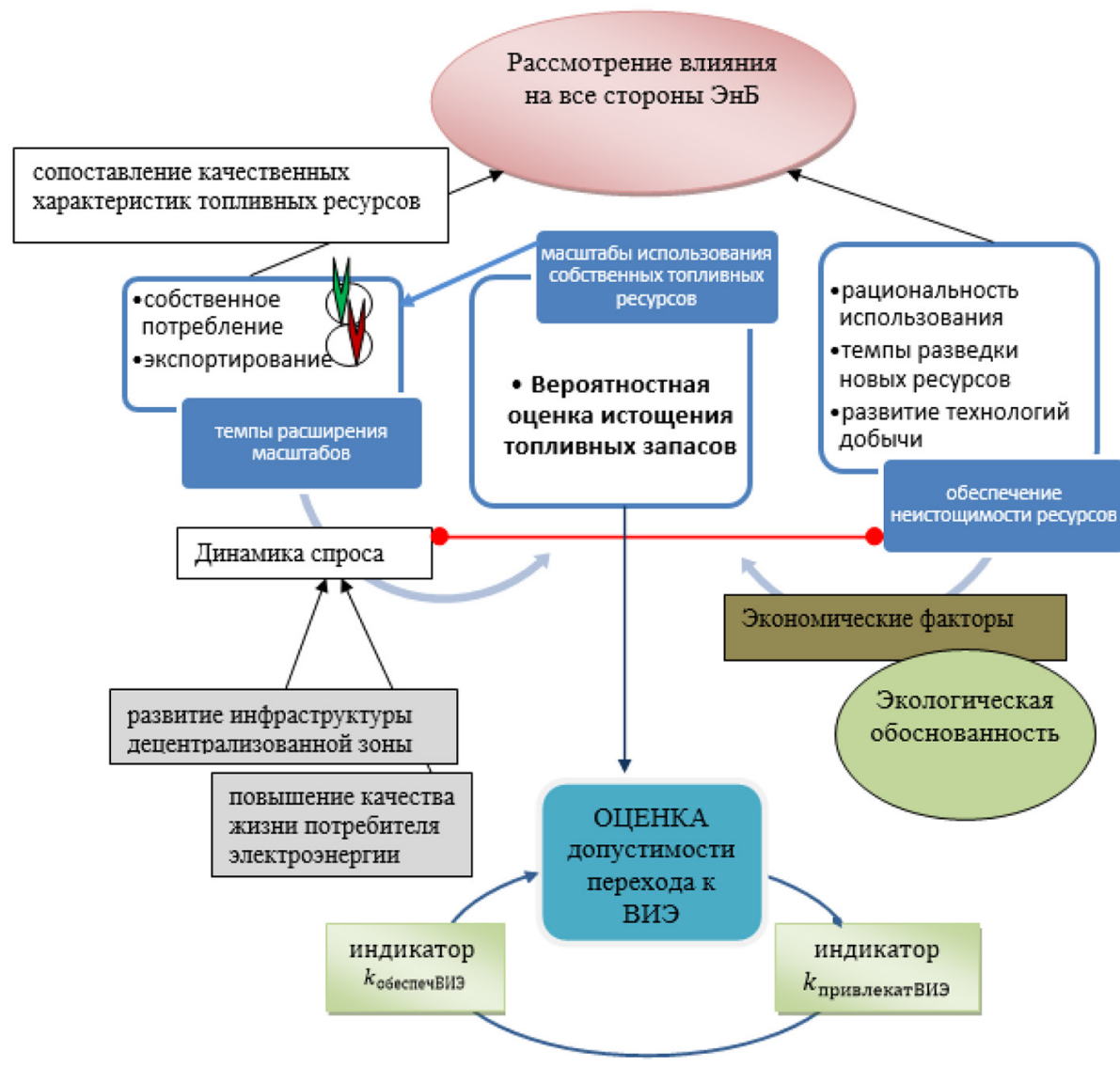

Рис. 3. Случайные и действительные факторы, оказывающие влияние на оценку истощения топливных ресурсов

Fig 3. Random and actual factors influencing the assessment of the depletion of fuel resources

рый все-таки в такой оценке показывает количественную характеристику. Но комплексность понятия требует рассмотрения и качественной стороны, в данном случае, например, сравнительной характеристики качества потребляемого и экспортируемого ресурса из собственных источников. Здесь же следует рассмотреть состояние минерально-сырьевой базы с вовлечением в отработку разрабатываемых месторождений и залежи с трудно извлекаемыми запасами (ТРИЗ), если таковые присутствуют на месторождениях децентрализованной зоны, возможности вовлечения в оборот открытых, разведанных месторождений.

Здесь же в индикаторе должно отслеживаться выявление причин истощения топливной базы (ресурсные проблемы, экологические воздействия, интенсивность развития хозяйств и т. д.), сопряженное и с проблемами ее освоения - менее благоприятные горно-геологические условия, экстремальные природные условия Севера и Арктики. Рассмотрение показателя истощения только со стороны прогноза вероятных сроков для удовлетворения объемов потребления даст одностороннюю картину для уровня ЭнБ. Скорость истощения топливных запасов условно определяется при соизмерении динамики роста потребления с темпами извлечения разведанных запасов, которые, очевидно, зависят от экономических факторов по объемам фи-

$$
-512-
$$


нансирования планов добычи топливных ресурсов и т. д. Восполнение запасов за счет различных направлений (энергосбережение, увеличение добычи полезных ископаемых, переход на возобновляемые локальные ресурсы, фактическое снижение объемов электропотребления и т. д.) и экологическая обоснованность расширения масштабов извлечения топливных ресурсов влияют на обеспечение энергетической безопасности территории.

Основными критериями вовлечения ВИЭ в повышение энергетической безопасности изолированных труднодоступных территорий Севера и Арктической зоны РФ являются (табл. 1): ресурсная значимость; экономическая значимость; экологическая значимость; энергетическая значимость. Дополнительного отдельного рассмотрения требуют критерии социальной, технологической (вне основной функции), финансово-экономической значимости и эффекта «региональной полезности».

Концепция достижения комплексной ценности (CV) ВИЭ в обеспечении ЭнБ определяется множеством факторов в оценке общего преимущества диверсификации топливных ресурсов возобновляемыми. Тогда измерение (CV) ВИЭ в ЭнБ осуществимо на рассмотрении схемы

Таблица 1. Методика количественных оценок критериев эффективности ВИЭв повышении энергетической безопасности децентрализованных энергозон

Table 1. Methodology for quantitative assessments of RES efficiency criteria in improving the energy security of decentralized energy zones

\begin{tabular}{|c|c|c|}
\hline $\begin{array}{c}\text { Наименование } \\
\text { группы индикаторов }\end{array}$ & $\begin{array}{l}\text { Условия формирования } \\
\text { градации }\end{array}$ & $\begin{array}{c}\text { Инструментарий анализа в измерении индикатора } \\
\text { и градация оценки его состояния }\end{array}$ \\
\hline 1 & 2 & 3 \\
\hline \multicolumn{3}{|c|}{ Критерий ресурсной (топливно-энергетической) значимости } \\
\hline \begin{tabular}{|l} 
Коэффициент \\
обеспеченности \\
возобновляемыми \\
ресурсами \\
децентрализованной \\
зоны \\
$\boldsymbol{k}_{\text {обспеч ВиЕ }}$
\end{tabular} & $\begin{array}{l}\text { - высокая или 100\%- } \\
\text { ная доля привозного } \\
\text { топлива при сложной } \\
\text { логистической схеме; } \\
\text { - высокий удельный } \\
\text { расход топлива; } \\
\text { - высокая стоимость } \\
\text { топливной составляющей } \\
\text { в себестоимости э/э; } \\
\text { - низкая надежность } \\
\text { АСЭС; } \\
\text { - экспертные оценки }\end{array}$ & $\begin{array}{l}\text { Соответствие потенциальных возможностей } \\
\text { ВИЭ условиям эффективного использования } \\
\text { гибридными или автономными установками для } \\
\text { характерных графиков электрических нагрузок } \\
\text { потребителей. Представляет комплексное } \\
\text { микроисследование (как переход к отдельному } \\
\text { глубокому расчету): } \\
\text { - природно-ресурсное: обработка } \\
\text { характеристических параметров (средняя сезонная } \\
\text { скорость ветрового потенциал, солнечная } \\
\text { инсоляция, объемы и распределение биомассы } \\
\text { и т. д.) возобновляемого энергоресурса территории; } \\
\text { - техническое: оценка технического потенциала } \\
\text { / единичных характеристик возобновляемого } \\
\text { энергоресурса территории по типовым методикам; } \\
\text { - энергетическое: оценка соотношения } \\
\text { с изменяющейся нагрузкой потребителя } \\
\text { (социальным статусом потребителя) } \\
\text { в рациональном выборе структуры АСЭС; } \\
\text { - топливно-энергетическое: оценка } \\
\text { сравнительного соотношения выработки } 1 \text { кВт'ч } \\
\text { электроэнергии потенциалом возобновляемых } \\
\text { и традиционных ресурсов в анализируемый } \\
\text { период, т. е. определение соответствия величине } \\
\text { заменяемого объема топливных ресурсов }\end{array}$ \\
\hline
\end{tabular}


Продолжение табл. 1

Continuation of Table. 1

\begin{tabular}{|c|c|c|}
\hline 1 & 2 & 3 \\
\hline \begin{tabular}{|l|} 
Коэффиичент \\
привлекательности \\
развития ВИЭ для \\
децентрализованной \\
зоньь
\end{tabular} & $\begin{array}{l}\text { - низкая надежность } \\
\text { АСЭС; } \\
\text { - высокие финансовые } \\
\text { затраты на обеспеченность } \\
\text { территории и объектов } \\
\text { ДСЭС; } \\
\text { - актуальные } \\
\text { предпосылки к развитию } \\
\text { возобновляемых } \\
\text { источников энергии } \\
\text { на территории } \\
\text { децентрализованной зоны; } \\
\text { - экспертные оценки }\end{array}$ & 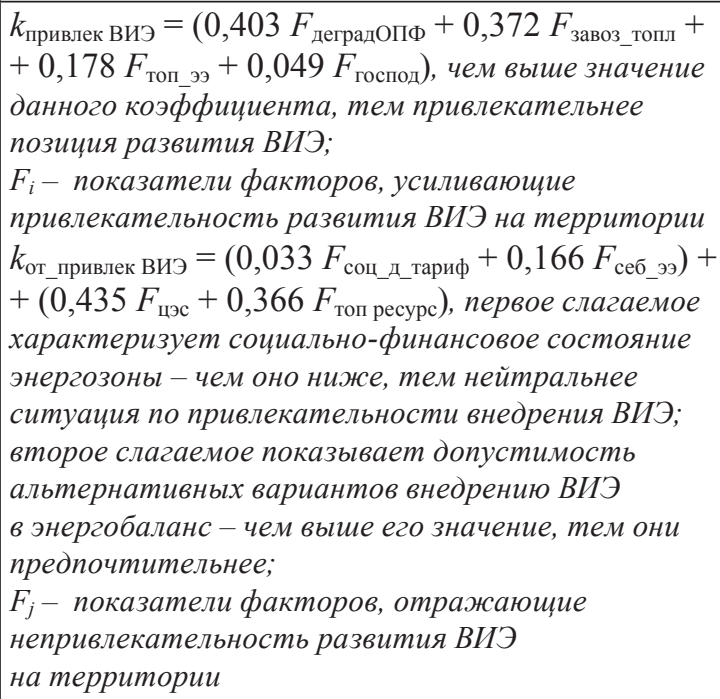 \\
\hline $\begin{array}{l}\text { Показатель } \\
\text { истошения } \\
\text { собственной } \\
\text { топливной базы }\end{array}$ & $\begin{array}{l}\text { - повышение топливной } \\
\text { составляющей } \\
\text { в себестоимости } \\
\text { электроэнергии } \\
\text { при переходе } \\
\text { к импортируемому } \\
\text { энергоресурсу в условиях } \\
\text { ценообразования } \\
\text { энергетики Севера; } \\
\text { - труднодоступность } \\
\text { месторождений, } \\
\text { недофинансирование } \\
\text { геологоразведки }(\mathrm{G}) ; \\
\text { - экспертные оценки }\end{array}$ & $\begin{array}{l}\text { При собственном использовании ресурсов } \\
\mathrm{V}_{\mathrm{i}}\left(\in \text { темп нарастания }-k_{н}\right) \\
=\left\{\begin{array}{c}\mathrm{Б}_{\mathrm{y}}, \mathrm{V}_{\mathrm{i}}:=k_{н} \downarrow \cup G \downarrow \\
\text { Д, } k_{H} \uparrow \cup G \downarrow \\
\mathrm{\Psi}, \mathrm{V}_{\mathrm{i}}^{\mathrm{z}}:=k_{н} \uparrow \cup G \rightarrow 0\end{array}\right. \\
\text { где } \mathrm{Б}_{\mathrm{y}}-\text { условно безопасное состояние, Д - } \\
\text { депрессивное, Ч - чрезвычайное. } \\
\text { При экспорте ресурсов любое положение } \\
\text { не улучшает состояние децентрализованной зоны } \\
\text { без факта индикатора «Возможность обеспечения } \\
\text { запасами нефти, угля, газа через разведку } \\
\text { месторождений децентрализованной зоны» }\end{array}$ \\
\hline \multicolumn{3}{|c|}{ Критерий энергетической значимости } \\
\hline \begin{tabular}{|l|} 
Коэффициент \\
структурной \\
обеспеченности \\
АСЭС на основе ВИЭ \\
децентрализованной \\
зоньи
\end{tabular} & $\begin{array}{l}\text { - неустойчивый характер } \\
\text { проявления потенциала } \\
\text { ВИЭ; } \\
\text { - экспертные оценки }\end{array}$ & 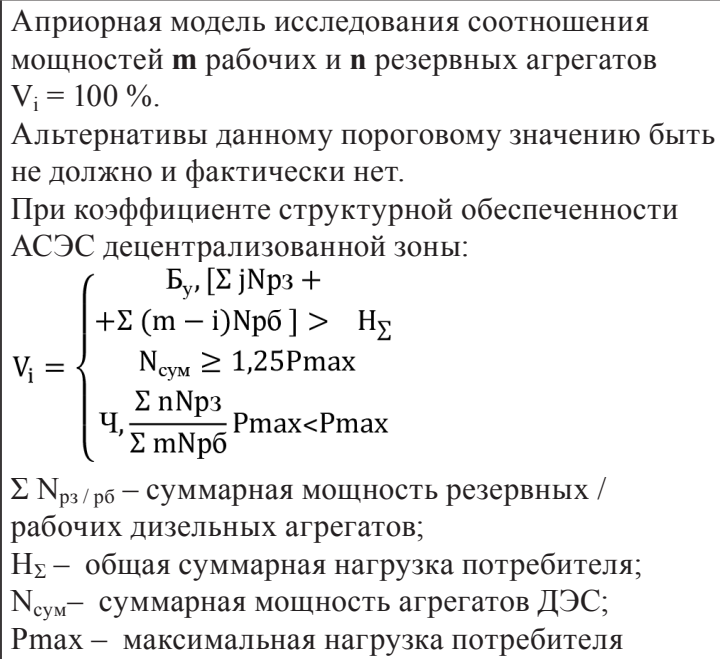 \\
\hline
\end{tabular}


Окончание табл. 1

Continuation of Table. 1

\begin{tabular}{|c|c|c|}
\hline 1 & 2 & 3 \\
\hline $\begin{array}{l}\text { Индикативный } \\
\text { показатель } \\
\text { степени износа } \\
\text { и повреждений } \\
\text { установок } \\
\text { на базе ВИЭ } \\
\text { децентрализованной } \\
\text { зоньл }\end{array}$ & $\begin{array}{l}\text { - требования } \\
\text { к климатическому } \\
\text { исполнению установок, } \\
\text { обслуживающему } \\
\text { персоналу; } \\
\text { - требования } \\
\text { к обеспечению надежного } \\
\text { электроснабжения } \\
\text { потребителей; } \\
\text { - экспертные оценки }\end{array}$ & $\begin{array}{l}\text { Очеека в соотночении со значением индикатора } \\
\text { «Синтетический индикативный показатель степени } \\
\text { износа ОПФ по АСЭС децентрализованной зоны» } \\
\mathrm{V}_{\mathrm{i}}=\left\{\begin{array}{c}\text { Б}_{\mathrm{y}}, \text { ФИ } \leq 30 \%, \text { признаки МИ; } \\
\text { Д, ФИ } \leq 40 \%, \text { МИ } 2 \text { вида, СИ; } \\
\text { Ч, ФИ }>50 \%, \text { МИ } 1 \text { и } 2 \text { вида, } \\
\text { ЭИ }\end{array}\right. \\
\text { физический износ (ФИ), моральньй износ (МИ), } \\
\text { социальный износ (СИ), экологический износ (ЭИ) }\end{array}$ \\
\hline \multicolumn{3}{|c|}{ Критерий экологической значимости } \\
\hline $\begin{array}{l}\text { Экологическое } \\
\text { воздействие } \\
\text { энергоустановок } \\
\text { на ВИЭ } \\
\text { на окружаюшую } \\
\text { среду с учетом } \\
\text { углеродного следа }\end{array}$ & $\begin{array}{l}\text { - низкая толерантность } \\
\text { конкретных } \\
\text { экосистем территории } \\
\text { к функционирующему } \\
\text { на ней энергохозяйству; } \\
\text { - предельно малая } \\
\text { плотность населения; } \\
\text { - повышенный удельный } \\
\text { расход топлива; } \\
\text { - низкие комфортные } \\
\text { условия проживания; } \\
\text { - экспертные оценки }\end{array}$ & $\begin{array}{l}\text { - неприемлемый уровень - ощущения } \\
\text { отрицательного воздействия на основе данных } \\
\text { и описаний специалистов, выраженных } \\
\text { в лингвистических оценках; } \\
\text { - благоприятный уровень - приемлемое } \\
\text { воздействие при эксплуатации с некоторым } \\
\text { воздействием при строительстве и монтаже; } \\
\text { присутствие объемов снижения вредных выбросов } \\
\text { в окружающую среду от замещения топлива } \\
\text { в традиционных энергоустановках }\end{array}$ \\
\hline \multicolumn{3}{|c|}{ Критерий экономической значимости } \\
\hline $\begin{array}{l}\text { Доля топливной } \\
\text { составляющей } \\
\text { в себестоимости } \\
\text { производства } \\
\text { электроэнергии, } \\
\text { производимой } \\
\text { гибридной АСЭС } \\
\text { на территории } \\
\text { децентрализованной } \\
\text { зонь }\end{array}$ & $\begin{array}{l}\text { - экспертные оценки; } \\
\text { - наложение высокой } \\
\text { топливной составляющей } \\
\text { на относительно } \\
\text { повышенный расход } \\
\text { топлива }\end{array}$ & 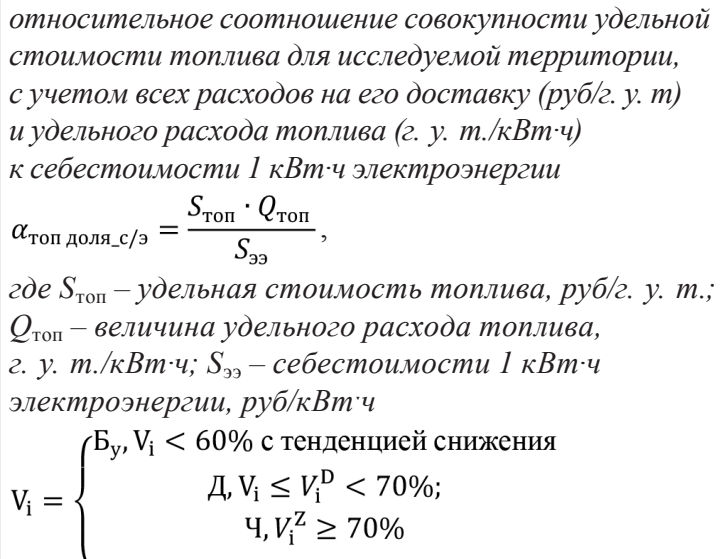 \\
\hline $\begin{array}{l}\text { Территориальный } \\
\text { коэффицииент } \\
k_{\text {терр инвест }}\end{array}$ & $\begin{array}{l}\text { - уровень развитости } \\
\text { совокупности } \\
\text { экономических, } \\
\text { социальных свойств, } \\
\text { суровость природных } \\
\text { и специфичность } \\
\text { географических условий; } \\
\text { - целесообразная } \\
\text { обоснованность развития } \\
\text { и сохранения точки } \\
\text { территории; } \\
\text { - экспертные оценки }\end{array}$ & $\begin{array}{l}\text { комплекс типовых расчетов индекса, } \\
\text { определяюшего соотношение между уровнем } \\
\text { интегрального риска и величиной совокупного } \\
\text { потенциала децентрализованной зоны } \\
\text { Чем ниже интегральный индекс соотношения, } \\
\text { который мы принимаем за территориальный } \\
\text { коэффициент, тем первостепеннее приоритетность } \\
\text { для безотлагательных инвестиций в данную } \\
\text { децентрализованную энергозону с учетом } \\
\text { обоснованного рассмотрения сохранения и развития } \\
\text { отдельных пунктов территории, тем выше степень } \\
\text { социальной и экономической оправданности } \\
\text { комплексного развития локального кластера }\end{array}$ \\
\hline
\end{tabular}


интегрирующей модели развертывания возобновляемых технологий на территории децентрализованной зоны электроснабжения, отображения приоритетов в балансе между эффектами и расходами, связанными с внедрением ВИЭ и снятием барьеров.

В представленной концепции хорошо видны возможности для территорий Севера и Apктических зон в сочетании со сложностями их использования. Для разных структур данная схема может являться ориентиром в принятии решения и создании материально-технического базиса электроснабжения на основе ВИЭ с консолидацией технико-экономического, информационного, финансового и производственного потенциала. Как показал анализ факторов децентрализованных зон Севера, в перечне основных рисков реализации проектов возобновляемой энергетики наиболее явно обозначаются [9]: технические риски, выраженные высоким моральным и техническим износом оборудования ДЭКЭС; финансово-экономические риски; социальные риски, в большей степени связанные с дефицитом квалифицированных кадров.

Использование ВИЭ в обеспечении ЭнБ [10-13] способствует расширению диапазона мер для поддержания условий реализации ее составляющих. А именно в слабых ее позициях, которые проявляются в ресурсной достаточности (100\%-ная доля использования привозного дизельного топлива в энергобалансе), в экономической доступности (низкие темпы обновления ОПФ и недостаточность инвестиций в ДЭКЭС), в технологической достижимости (снижение темпов геологоразведки местных месторождений, высокий показатель износа ОПФ, морально устаревшие технологии на объектах локальной энергетики). В каждой категории (в энергообеспечении, в развитии топливных ресурсов, в энергетической политике, в социальноэкологическом аспекте и т. д.) ВИЭ играют свою роль и в целом могут оказать заметное влияние в обеспечении спроса и предложения соответствующих энергоносителей, что лежит в основе обеспечения ЭнБ, согласно Доктрине энергетической безопасности РФ [14].

Роль ВИЭ при внедрении технологии возобновляемой энергетики - это влияние на другие процессы, такие как смягчение экологической обстановки, повышение надежности энергоснабжения, снижение загрузки энергетического оборудования, изменение экономических показателей выработки и передачи энергии и т. п. Организация условий - это создание возможностей для осуществления данного влияния.

За 2020 г. объем вводов новых генерирующих мощностей электрической энергии на основе возобновляемых источников энергии составил по России 1,2 ГВт. Созданы предпосылки для осуществления мероприятий по модернизации неэффективной генерации, в том числе в удаленных и изолированных районах страны, с использованием механизмов конкурсных отборов проектов ВИЭ. Кроме того, предусмотрены меры поддержки локализации основного оборудования объектов возобновляемой энергетики. Продолжена реализация федерального проекта «Гарантированное обеспечение доступной электроэнергией», призванного обеспечить развитие централизованных энергосистем, включая распределенную генерацию на основе ВИЭ в удаленных и изолированных энергорайонах. В целях развития распределенной генерации, в том числе на основе ВИЭ, в 2020 г. усовершенствована нормативная база по предоставлению проектам в сфере возобновляемой энергетики на розничных рынках электрической энергии, в том числе в изолированных территориях, мер государственной поддержки [15-17]. 


\section{Выводы}

Указанные аспекты создают возможности для ВИЭ конкурировать по рентабельности и привлекательности $[7,18]$ в качестве источника электроэнергии для изолированных труднодоступных потребителей. Энергетическая безопасность имеет решающее значение при вовлечении ВИЭ [7, 8, 19-21]. При увеличении количества источников энергии в гибридной автономной структуре необходимо предвидеть не только существующие, но и новые вызовы энергетической безопасности, управлять ими. Это требует обеспечения устойчивого и приемлемого сочетания возобновляемой энергии и технологий, рационального и грамотного сочетания возобновляемых и традиционных ресурсов, наилучшего использования существующей инфраструктуры, устойчивости к изменениям климата [22], защиты от киберрисков, гарантированного объема качественного традиционного топлива.

\section{Список литературы /References}

[1] Lukutin B., Kiushkina V. Intellectual energy security monitoring of decentralized systems of electricity with renewable energy sources. International Conference Green Energy and Smart Grids: E3S Web of Conferences, 2018, 69. https://doi.org/10.1051/e3sconf/20186902002

[2] Bogdanov D., Breyer C. North-East Asian super grid for $100 \%$ renewable energy supply: optimal mix of energy technologies for electricity, gas and heat supply options. Energy Conversion and Management, 2016, 112. 176-190. https://doi.org/10.1016/j.enconman.2016.01.019

[3] Gordievsky E., Sirotkin E., Miroshnichenko A. Development of mobile power complex model on renewable energy sources for autonomous electrical supply of Russian Far Eastern region. Proceedings - 2019 International Ural Conference on Electrical Power Engineering, UralCon (Chelyabinsk, 1-3 October 2019). Chelyabinsk: IEEE, 2019. P. 148-153. https://doi.org/10.1109/ URALCON.2019.8877665

[4] Elistratov V., Kudryasheva I. Regimes, management and economics of energy complexes on the basis of renewable energy sources for autonomous power supply. International Scientific and Technical Conference Smart Energy Systems 2019: E3S Web of Conferences, 2019, 124. https://doi. org/10.1051/e3sconf/201912404023

[5] Киушкина В.Р. Эффекты вовлечения ВИЭ в мониторинге состояния энергетической безопасности северных и арктических зон РФ. Энергетическая политика, 2018, 4, 109-117. [Kiushkina VR. Effects of involvement of renewable energy sources in monitoring the state of energy security of the northern and arctic zones of the Russian Federation. Energy policy. 2018, 4, 109-117. (In Russian)]

[6] Miroshnichenko A., Sirotkin E., Bodrova E. On the possibility to solve the problems of electrical power supply to autonomous consumers by using renewable energy sources. International Multi-Conference on Industrial Engineering and Modern Technologies (Vladivostok, 1-4 October 2019). Vladivostok: IEEE, 2019. https://doi.org/10.1109/FarEastCon.2019.8934390

[7] Лукутин Б. В., Киушкина В.Р. Влияние возобновляемой энергетики на энергетическую безопасность децентрализованных систем электроснабжения. Журнал СФУ. Техника и технологии, 2020, 13(5), 632-642. DOI: 10.17516/1999-494X-0252 [Kiushkina V, Lukutin B. The impact of renewable energy on the energy security of decentralized power supply systems. J. Sib.Fed.Univ. Eng. technol., 2020, 13(5), 632-642. (In Russian)]

$$
-517-
$$


[8] Лукутин Б. В., Киушкина В. Р. Характеристики энергетической безопасности децентрализованного района и автономного объекта электрификации. Вестник Иркутского государственного технического университета, 2021, 25(1), 66-79. https://doi.org/10.21285/1814-35202021-1-66-79 [Kiushkina V, Lukutin B. Characteristics of energy security of decentralized area and autonomous electrification object. Bulletin of the Irkutsk State Technical University, 2021, 21(1), 66-79. (In Russian)]

[9] Violetta Kiushkina, Boris Lukutin. Matrix of vulnerability of decentralized areas to local energy security risks in the northern and arctic zones in the structural set of solutions. E3S Web of Conferences 209, 06012 (2020) ENERGY-21 - Sustainable Development \& Smart Management. Session Reliability of Fuel and Energy Supply to the Consumer, Energy Security. Volume 209, 2020. Number of page(s): 6

[10] Wang, Q, Yang, X. Investigating the sustainability of renewable energy - An empirical analysis of European Union countries using a hybrid of projection pursuit fuzzy clustering model and accelerated genetic algorithm based on real coding. Journal of Cleaner Production. Volume 268, 20 September 2020. https://doi.org/10.1016/j.jclepro.2020.121940

[11] Azzuni A., Aghahosseini A., Ram M., Bogdanov D., Caldera U., Breyer C. Energy security analysis for a $100 \%$ renewable energy transition in Jordan by 2050. Sustainability (Switzerland). Volume 12, Issue 12, 1 June 2020, Page 4921. https://doi.org/10.3390/su12124921

[12] Smirnova E., Senderov S. Energy security problems at the regional level: Situation analysis and main trends. E3S Web of Conferences Regional Energy Policy of Asian Russia, volume 77 (2019), [01009]. https://doi.org/10.1051/e3sconf/20197701009

[13] Senderov S., Rabchuk V. On the system of key indicators for monitoring the compliance with requirements of the Russia's Energy Security Doctrine in terms of reliable fuel and energy supply to domestic consumers of energy resources. E3S Web of Conferences Rudenko International Conference on Methodological Problems in Reliability Study of Large Energy Systems, (RSES2019), volume 139 (2019), [01007]. https://doi.org/10.1051/e3sconf/201913901007

[14] Доктрина Энергетической безопасности Российской Федерации (утверждена Указом Президента Российской Федерации от 13.09.2019 г. № 216). [Doctrine of Energy Security of the Russian Federation. Moscow, 2019, 19. (in Russian)]

[15] Правительство усовершенствовало механизмы поддержки проектов возобновляемой энергетики на розничных рынках. Новости Минэнерго России. [Электронный ресурс] - Режим доступа: https://minenergo.gov.ru/node/18708 - Заглавие с экрана. [The government has improved mechanisms to support renewable energy projects in retail markets. Russian Ministry of Energy News. [Electronic resourse] - Access: https://minenergo.gov.ru/node/18708]

[16] Рекомендации «круглого стола» Комитета Государственной Думы по энергетике на тему «Возобновляемые источники энергии: состояние российского законодательства, перспективы развития и пути совершенствования, в том числе на примере энергообеспечения изолированных территорий», утвержденные решением Комитета Государственной Думы по энергетике, № 3.25-5/154 от 16.09.2020 г. [Электронный ресурс] - Режим доступа: http://www. komitet2-13.km.duma.gov.ru/Rabota/Rekomendacii-po-itogam-meropriyatij/item/23674715/ - Заглавие с экрана. [Recommendations of the «round table» of the State Duma Committee on Energy on the topic «Renewable Energy Sources: the State of Russian Legislation, Development Prospects and Ways 
to Improve, Including the Example of Power Supply for Isolated Areas», approved by the decision of the State Duma Committee on Energy, № 3.25-5 / 154, 16.09.2020. [Electronic resourse] - Access: http://www.komitet2-13.km.duma.gov.ru/Rabota/Rekomendacii-po-itogam-meropriyatij/item/ 23674715/]

[17] Федеральный закон от 27.12.2019 г. № 471-Ф3 «О внесении изменений в Федеральный закон «Об электроэнергетике» в части развития микрогенерации» [Federal Law of December 27, 2019 № 471 «On Amendments to the Federal Law» On Electricity «in terms of the development of microgeneration» (in Russian)]

[18] Лесных Ю.Г. Возможности возобновляемых источников энергии для обеспечения экономической и энергетической безопасности интегрированных социально-экономических пространств. Национальные интересы: приоритеты и безопасность, 2011, 21(114), 60-67 [Lesnykh Y.G. Possibilities of renewable energy sources to ensure economic and energy security of integrated socio-economic spaces. National interests: priorities and security, 2011, 21(114), 60-67 (in Russian)]

[19] Ang, B.W., Choong, W.L. Email Author, Ng, T. S. Energy security: Definitions, dimensions and indexes. Renewable and Sustainable Energy Reviews. Volume 42, February 2015, Pages 10771093. https://doi.org/10.1016/j.rser.2014.10.064

[20] Choong, W.L., Ang, B.W., Ng, T.S. Going green and energy security. IEEE Computer Society. Proceedings of the 2014 International Conference and Utility Exhibition on Green Energy for Sustainable Development, ICUE2014. URL: https:/ezproxy.ha.tpu.ru:2219/record/display.uri?eid=2s2.0 $-84903743949 \&$ origin $=$ resultslist\&sort $=$ plf $-\mathrm{f} \& \mathrm{src}=\mathrm{s} \& \mathrm{sid}=\mathrm{db} 280 \mathrm{a} 58 \mathrm{a} 35004 \mathrm{e} 3 \mathrm{~d} 34275720 \mathrm{dfbaea} 2$ $\&$ sot=autdocs \&sdt=autdocs \&sl=18\&s=AU-ID\%2856245053300 \%29\&relpos $=2 \&$ citeCnt $=0 \&$ searchT erm $=$

[21] Pasqualetti M.J., Sovacool B.K. The importance of scale to energy security. Journal of Integrative Environmental Sciences. Volume 9, Issue 3, September 2012, Pages 167-180. https://www. tandfonline.com/doi/full/10.1080/1943815X.2012.691520

[22] Новак А. Баланс углеводородных и возобновляемых источников энергии - климатическая повестка и энергетическая безопасность планеты. Энергетическая политика, 2021, 6(160), 5-11 [Novak A. Balance of Hydrocarbon and Renewable Energy Sources - Climate Agenda and Energy Security of the Planet. Energy policy, 2021, 6(160), 5-11 (in Russian)] 